\title{
Outcome after Gamma Knife surgery for intracranial arteriovenous malformations in children
}

\author{
Clinical article
}

\author{
Noriko Tamura, M.D., ${ }^{1}$ Motohiro Hayashi, M.D., D.Med.Sci.. ${ }^{1,2}$ \\ Mikhail Chernov, M.D., D.Med.Sci., ${ }^{1,2}$ Manabu Tamura, M.D., D.Med.Sci.., ${ }^{1,2}$ \\ Ayako Horiba, M.D., ${ }^{1}$ Yoshiyuki Konishi, Ph.D., ${ }^{2}$ Yoshihiro Muragaki, M.D., Ph.D., ${ }^{1,2}$ \\ Hiroshi Iseki, M.D., Ph.D., ${ }^{1,2}$ and Yoshikazu OKada, M.D., Ph.D. ${ }^{1}$
}

${ }^{I}$ Department of Neurosurgery, Neurological Institute, and ${ }^{2}$ Faculty of Advanced Techno-Surgery, Institute of Advanced Biomedical Engineering and Science, Tokyo Women's Medical University, Tokyo, Japan

\begin{abstract}
Object. The focus of the present study was the evaluation of outcomes after unstaged and staged-volume Gamma Knife surgery (GKS) in children harboring intracranial arteriovenous malformations (AVMs).

Methods. Twenty-two children (median age 9.5 years) underwent GKS for AVMs and were followed up for at least 2 years thereafter. The disease manifested with intracranial hemorrhage in $77 \%$ of cases. In $68 \%$ of patients the lesion affected eloquent brain structures. The volume of the nidus ranged from 0.1 to $6.7 \mathrm{~cm}^{3}$. Gamma Knife surgery was guided mainly by data from dynamic contrast-enhanced CT scans, with preferential targeting of the junction between the nidus and draining vein. The total prescribed isodose volume was kept below $4.0 \mathrm{~cm}^{3}$, and the median margin dose was $22 \mathrm{~Gy}$ (range 20-25 Gy). If the volume of the nidus was larger than $4.0 \mathrm{~cm}^{3}$, a second radiosurgical session was planned for 3-4 years after the first one. Nine patients in the present series underwent unstaged radiosurgery, whereas staged-volume treatment was scheduled in 13 patients.

Results. Complete obliteration of the AVM was noted in $17(77 \%)$ of 22 patients within a median period of 47 months after the last radiosurgical session. Complete obliteration of the lesion occurred in $89 \%$ of patients after unstaged treatment and in $62.5 \%$ after staged GKS. Four (67\%) of 6 high-grade AVMs were completely obliterated. Complications included 3 bleeding episodes, the appearance of a region of hyperintensity on $\mathrm{T}_{2}$-weighted MR images in 2 patients who had no symptoms, and reappearance of the nidus in the vicinity of the completely obliterated AVM in 1 patient.

Conclusions. Radiosurgery is a highly effective management option for intracranial AVMs in children. For larger lesions, staged GKS may be applied successfully. Initial targeting of the nidus adjacent to the draining vein and application of a sufficient radiation dose to a relatively small volume $\left(\leq 4 \mathrm{~cm}^{3}\right)$ provides a good balance between a high probability of obliteration and a low risk of treatment-related complications.

(http://thejns.org/doi/abs/10.3171/2012.7.GKS12998)
\end{abstract}

\section{Key Words - Gamma Knife surgery - stereotactic radiosurgery • staged radiosurgery $\quad$ - pediatric arteriovenous malformation $\bullet$ treatment $\bullet$ treatment outcome}

$\mathrm{C}$ URRENTLY GKS represents a widely approved option in the treatment of intracranial AVMs. Overall, this procedure provides lesion obliteration in $55 \%-76 \%$ of cases. ${ }^{2,8,21}$ The size of the nidus, however, is the main limitation on the effective application of GKS. In cases of large AVMs, the traditional radiosurgical strategy, based on complete coverage of the nidus with a prescribed isodose, requires a more or less prominent reduction in the radiation dose to avoid possi-

Abbreviations used in this paper: AVM = arteriovenous malformation; DS = digital subtraction; GKS = Gamma Knife surgery; PIV $=$ prescribed isodose volume. ble treatment-related complications. It reduces the probability of obliteration and usually necessitates repeated treatment. ${ }^{10,11,37}$ On the other hand, consecutive use of different modalities (microsurgery, embolization, or radiosurgery) is sometimes advocated for the treatment of high-grade AVMs, ${ }^{7,17-19,27}$ although the corresponding cumulative risk of morbidity may be significant. Finally, a wait-and-see policy in such cases has been proposed as well, ${ }^{44}$ but it leaves the patient with a life-long risk of intracranial hemorrhage.

During the last decade staged-volume GKS with sequential high-dose irradiation of different parts of the lesion separated by sufficiently long time intervals has ob- 
tained wide, albeit not uniform, acceptance for the management of large AVMs. ${ }^{1,2,5,14-16,23}$ In our clinic this technique is used routinely with special emphasis on initial targeting of the portion of nidus adjacent to the draining vein in an attempt to affect the main arteriovenous shunts, slow intralesional blood flow, and, finally, cause thrombosis. This treatment strategy has demonstrated high effectiveness, particularly in high-grade AVMs, and has been associated with minimal risk of complications. ${ }^{14-16}$ Moreover, it may be especially effective in children, since pediatric AVMs may be more sensitive to irradiation. ${ }^{36,46}$

The objective of the present study was the evaluation of outcomes after unstaged and staged-volume GKS of intracranial AVMs in children.

\section{Methods}

Between February 2002 and October 2009, 138 consecutive patients underwent GKS in the Department of Neurosurgery of the Tokyo Women's Medical University for management of intracranial AVMs. This group included 26 children (age < 16 years), and 22 of them were followed up for at least 2 years after radiosurgery. Those 22 patients were evaluated in the present retrospective study. None of the other 4 pediatric patients had verified AVM obliteration, experienced intracranial hemorrhage, underwent additional treatment, or died during the latency period after radiosurgery.

\section{Clinical Data}

There were 14 boys and 8 girls. Their ages ranged from 4 to 14 years (median 9.5 years). Two children were younger than 5 years old, 11 ranged in age from 5 to 10 years, and 9 were older than 10 years. The disease manifested with intracranial hemorrhage in 17 cases (77\%), seizures in 2 cases $(9 \%)$, and neurological deficit in 1 case $(4.5 \%)$. Two lesions (9\%) were discovered incidentally. Four patients underwent another treatment for their AVMs before GKS: embolization ( 2 cases), open resection (1 case), and embolization followed by resection (1 case).

The lesions were located in the frontal lobe in 5 cases; temporal lobe in 2 cases; occipital lobe in 5 cases; basal ganglia and thalamus in 6 cases; and corpus callosum, cerebral peduncle, cerebellum, and within the cerebral ventricle in 1 case each. Eloquent brain structures were affected in 15 patients (68\%). According to the 3-tier classification proposed by Spetzler and Ponce, ${ }^{44} 8$ AVMs corresponded to Class A, 8 to Class B, and 6 to Class C (Table 1), whereas according to the Spetzler-Martin Scale, ${ }^{43}$ Grade II lesions were the most frequent (8 cases). The types of AVM angioarchitecture ${ }^{48}$ were defined as intermediate fast-flow fistulous in 5 cases, intermediate slow-flow moderate plexiform in 10 cases, and plexiform in 7 cases. The volume of the nidus at the time of radiosurgery varied from 0.1 to $6.7 \mathrm{~cm}^{3}$ (mean $2.7 \mathrm{~cm}^{3}$, median $1.2 \mathrm{~cm}^{3}$ ). The Pollock-Flickinger radiosurgery-based AVM score ${ }^{38}$ varied from 0.21 to 0.9 (mean 0.53 ).

\section{Radiosurgery}

Before December 2002, radiosurgery was performed using the Leksell Gamma Knife model B, and later patients
TABLE 1: Types of AVM in the present series of pediatric patients

\begin{tabular}{ccc}
\hline $\begin{array}{c}\text { Class According to the Spetzler- } \\
\text { Ponce 3-Tier Classification }\end{array}$ & $\begin{array}{c}\text { Spetzler-Martin } \\
\text { Grade }\end{array}$ & $\begin{array}{c}\text { No. of } \\
\text { Cases }\end{array}$ \\
\hline A & II & 8 \\
B & III & 6 \\
& VI (inoperable) & $2^{*}$ \\
C & IV & 5 \\
& V & 1 \\
\hline
\end{tabular}

* Both AVMs were located in the basal ganglia and thalamus.

were treated with model $4 \mathrm{C}$ with the Automatic Positioning System (Elekta AB). General anesthesia with remote control monitoring was applied throughout all stages of the procedure in 3 children, ${ }^{22}$ whereas in the others, manipulations were performed with the aid of local anesthesia. On the day of treatment, the Leksell G stereotactic frame (Elekta $\mathrm{AB}$ ) was affixed to the patient's head. If perilesional brain edema ${ }^{25}$ was noted, steroid medications were administered before treatment. Dynamic helical contrast-enhanced CT (slice thickness $1.0 \mathrm{~mm}$; contrast agent injection speed 3 $\mathrm{ml} /$ second; scanning delay 20 seconds), T2-weighted (slice thickness $2 \mathrm{~mm}$ ) and gadolinium-enhanced time-of-flight (slice thickness $1.0 \mathrm{~mm}$ ) MRI, and DS angiography were performed under stereotactic conditions. All imaging data were transferred via the Intranet to a workstation running the Leksell GammaPlan (initially version 5.34 and later version 8.3, Elekta $\mathrm{AB}$ ).

Radiosurgical treatment planning was performed within a 3D workspace with a simultaneous onscreen display of all obtained images. Treatment planning was mainly referenced to data from contrast-enhanced CT scans, which clearly demonstrated the junction between the nidus and draining vein, where the main shunts of the AVM are located. According to our treatment concept, this part of the lesion should be preferentially targeted, and therefore it was covered with multiple small (4- and $8-\mathrm{mm}$ ) isocenters, while the total PIV was kept below 4.0 $\mathrm{cm}^{3}$. This target volume permits the application of a sufficient radiation dose $(\geq 22$ Gy directed to the $50 \%$ isodose line), providing a high probability of nidus obliteration with a limited risk of possible treatment-associated complications. If the volume of the nidus was larger than 4.0 $\mathrm{cm}^{3}$, the second radiosurgical session was usually scheduled 3-4 years after the first. The second session was performed following similar treatment principles. Nine patients in the present series underwent unstaged radiosurgery. Staged-volume GKS was planned for 13 patients (Table 2); among them only 1 patient is still awaiting the second stage of treatment.

After completion of the CT-based treatment planning, the position of the PIV was adjusted according to the data provided by MR imaging and DS angiography. Special emphasis was placed on selective irradiation of the nidus itself, as well as the creation of a wide $80 \%$ isodose area within the target for attainment of the optimal homogeneous therapeutic effect. ${ }^{32}$ The radiation doses to adjacent eloquent structures were checked and constantly kept lower than $10 \mathrm{~Gy}$ for the visual pathways and lower 
TABLE 2: Volumes of AVM nidi in patients in the present series

\begin{tabular}{lccc}
\hline \multirow{2}{*}{\multicolumn{1}{c}{ Treatment Strategy }} & \multicolumn{3}{c}{ Vol of AVM Nidus $\left(\mathrm{cm}^{3}\right)$} \\
\cline { 2 - 4 } & Mean & Median & Range \\
\hline planned unstaged GKS (9 patients) & 1.1 & 1.1 & $0.1-3.2$ \\
planned staged-volume GKS (13 patients) & 3.8 & 4.4 & $1.1-6.7$ \\
whole cohort (22 patients) & 2.7 & 1.2 & $0.1-6.7$ \\
\hline
\end{tabular}

than 14 Gy for the brainstem. The radiosurgical parameters used in the present series of patients are presented in Table 3.

\section{Follow-Up Examinations}

All patients were followed up by their treating neurosurgeon with clinical examinations, as well as MR imaging and MR angiography or CT angiography sessions, which were scheduled every 6 months during the first 3 years after radiosurgery and annually thereafter. Additionally, the patients' relatives were advised to attend the outpatient clinic in case any neurological deterioration had occurred. Cerebral angiography was performed if additional treatment was planned for the AVM or for confirmation of complete obliteration of the lesion. The length of follow-up varied from 29 to 92 months.

\section{Results}

\section{Early Complications}

One patient who had a history of 2 intracerebral-intraventricular hemorrhages and an AVM extending into the cerebral ventricle experienced an additional episode of bleeding the day after GKS; however, this patient fully recovered and complete obliteration of the nidus was finally obtained. No early complications or side effects after radiosurgery were observed in any other patient in the present series.

\section{Obliteration Rate}

Overall, complete obliteration of the AVM was noted in $17(77 \%)$ of 22 patients within a median period of 47 months (range 19-82 months) after the last radiosurgical session. In 9 cases complete AVM obliteration was confirmed by DS angiography; in 6 cases by MR imaging and MR angiography; in 1 case by MR imaging, MR angiography, and CT angiography; and in 1 case by CT angiography alone. Specifically, complete obliteration was obtained in $4(67 \%)$ of 6 patients with high-grade (Class $\left.\mathrm{C}^{44}\right)$ AVMs.

In $12(92 \%)$ of 13 patients durable complete oblitera-

TABLE 3: Radiosurgical parameters in the present series of pediatric patients with intracranial AVMs

\begin{tabular}{lrcc}
\hline Radiosurgical Parameter & Mean & Median & Range \\
\hline PIV $\left(\mathrm{cm}^{3}\right)$ & 2.1 & 1.9 & $0.4-6.9$ \\
margin dose (Gy) & 22.6 & 22 & $20-25$ \\
max dose (Gy) & 48.8 & 44 & $36.3-50$ \\
no. of isocenters & 7.2 & 7 & $1-15$ \\
\hline
\end{tabular}

tion of the nidus was noted within a median period of 43 months (range 19-82 months) after the first radiosurgical session. Eight of these patients were initially scheduled for unstaged GKS because of the small volumes of their AVMs; in this subgroup the complete obliteration rate was $89 \%$ ( 8 of 9 patients). Four additional patients were initially scheduled for staged-volume radiosurgery, but the lesion was completely obliterated after the first procedure, despite incomplete coverage with the prescribed isodose at the time of treatment.

Among 8 patients, who underwent scheduled 2-staged GKS, complete obliteration of the nidus was observed in $5(62.5 \%)$ within a median period of 24 months (range 12-41 months) after the second treatment. One patient with an unobliterated AVM underwent a third stage of treatment, but complete obliteration of the lesion was still not obtained. One additional patient underwent an unscheduled staged GKS. In this case, the primary unstaged treatment led to complete obliteration of the nidus; however, a new portion of AVM appeared in the vicinity of the previous target, and the patient underwent radiosurgery once again. In this case complete obliteration has not yet been obtained.

\section{Factors Associated With AVM Obliteration}

A greater margin dose $(p=0.01$, Student t-test $)$ and maximum dose $(p=0.04$, Student $t$-test $)$ of radiation were associated with a higher probability of AVM obliteration. Other factors, namely patient age and sex, type of disease presentation, previous hemorrhage, Spetzler-Martin AVM grade, type of AVM angioarchitecture, presence of deep venous drainage, previous treatment, nidus volume, Pollock-Flickinger score, and number of isocenters used for GKS, did not show statistically significant associations with obliteration of the nidus.

\section{Late Complications}

Two incompletely obliterated AVMs with partial extension into cerebral ventricles bled at 20 and 60 months after irradiation. Both of these cases were scheduled for staged GKS. The annual hemorrhage rate in that subgroup of patients was $2.8 \%$. The appearance of a region of hyperintensity adjacent to the target area on T2weighted MR images was noted in 2 patients who had no symptoms. In one of these patients the hyperintense area appeared after the first radiosurgical session, and in the other one, it appeared after the second radiosurgical session. Finally, as mentioned earlier, reappearance of an AVM in the vicinity of the initial target after effective primary treatment was noted in 1 patient and required a second GKS.

\section{Illustrative Case}

An AVM located in the left basal ganglia and thalamus was disclosed incidentally in a 13-year-old girl who displayed no neurological symptoms or signs. The lesion was considered inoperable (Spetzler-Martin Grade VI); however, given the child's long life expectancy and the lesion's high cumulative risk of hemorrhage, radiosurgery 
was planned. Despite the AVM's relatively small volume, we decided to perform staged treatment with the goal of providing a sufficient radiation dose for greater probability of obliteration while minimizing the potential risk of complications. The first stage of GKS was performed by directing 22 Gy to the $55 \%$ isodose line in the portion of nidus mainly located in the thalamus (Fig. 1 upper). The second stage was performed 1.5 years later by using the same radiosurgical parameters for the portion of nidus mainly located in the basal ganglia (Fig. 1 lower). No complication or side-effect was noted after treatment. At 2 years after the second radiosurgical session, MR angiography revealed no evidence of a residual nidus (Fig. 2). The patient remains asymptomatic.

\section{Discussion}

The effectiveness of GKS for AVMs in children is well established. This treatment provides a high probability of complete obliteration of the lesion, which ranged
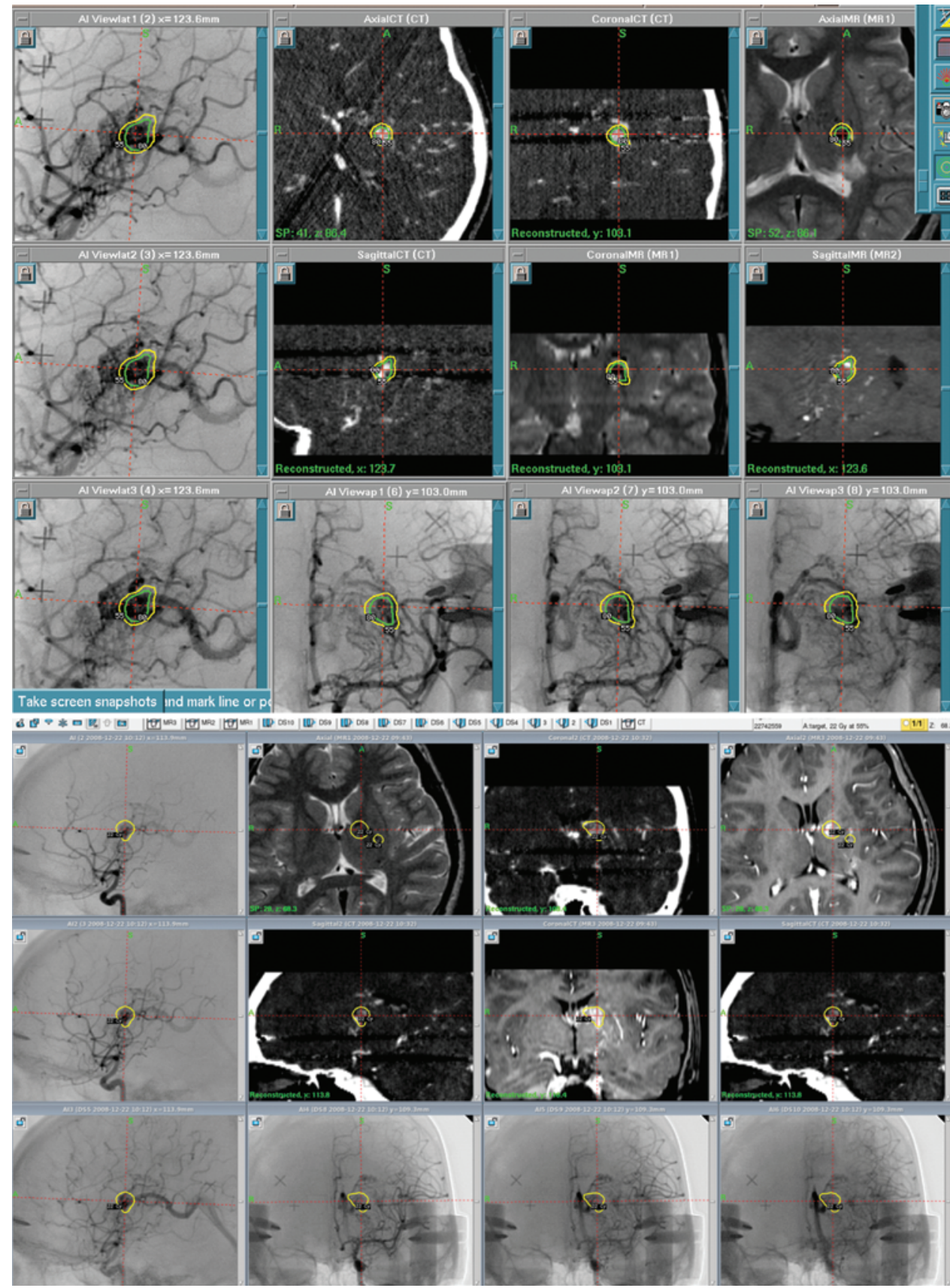

FIG. 1. Radiosurgical treatment plan for an inoperable, incidentally discovered AVM in the left basal ganglia and thalamus. The first GKS was performed by directing $22 \mathrm{~Gy}$ to the $55 \%$ isodose line in the portion of nidus mainly located in the thalamus (upper), whereas 1.5 years later the same radiosurgical parameters were used for management of the portion of nidus mainly located in the basal ganglia (lower). 


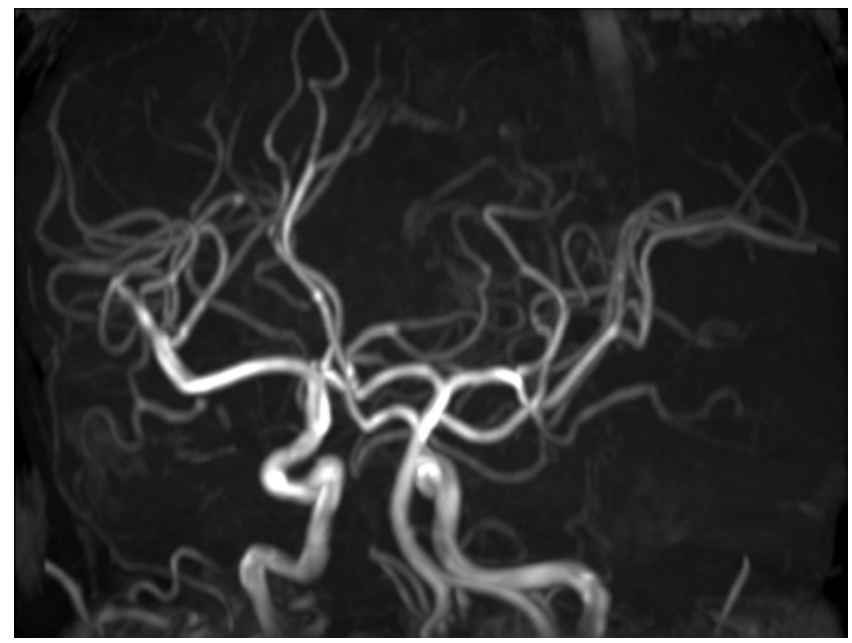

FIG. 2. Follow-up MR angiography obtained 2 years after 2-staged GKS was performed to treat the incidentally discovered AVM in the left basal ganglia and thalamus (see Fig. 1). No residual nidus is evident.

from $60 \%$ to $90 \%$ in the majority of reported series (Table 4). Comparable results can be obtained using linear accelerator-based radiosurgery as well.,34,39 Moreover, there is some evidence that AVMs in children are more sensitive to irradiation than those in adults ${ }^{46}$ and that the younger age of the patient is positively associated with the likelihood of treatment success ${ }^{38,41,50}$ and its earlier appearance. ${ }^{36}$ Radiosurgery may be particularly helpful for management of the multiple lesions associated with Rendu-Osler-Weber disease. ${ }^{29}$ In addition, radiosurgical treatment not only leads to a decrease in hemorrhage risk due to obliteration of the AVM, but frequently results in resolution of neurological symptoms such as headache and seizures. ${ }^{12,45}$

In our series, the overall obliteration rate for pediatric AVMs after GKS was 77\%, but it reached $89 \%$ in the subgroup of patients who received unstaged treatment, which was selected because of the small size of the lesions. In fact, the volume of the nidus and the delivered dose of radiation represent 2 primary interrelated factors determining the effectiveness of radiosurgery for AVMs. The necessity of decreasing the radiation dose in the treatment of larger lesions to prevent treatment-related complications negatively influences obliteration rates and significantly challenges their management. ${ }^{10,33,37,42}$

Recently, the technique of staged-volume GKS has opened new perspectives in cases of large and giant AVMs. However, the results reported to date are still contradictory: complete obliteration rates vary from $23 \%$ to $74 \%$, whereas the incidence of major complications other than hemorrhage range from $0 \%$ to $40 \%{ }^{1,2,5,23}$ Such significant variability may be caused, in part, by differences in treatment strategy with regard to target selection, PIV, applied radiation doses, number of treatment stages,

TABLE 4: Literature review of outcomes after GKS for intracranial AVMs in children*

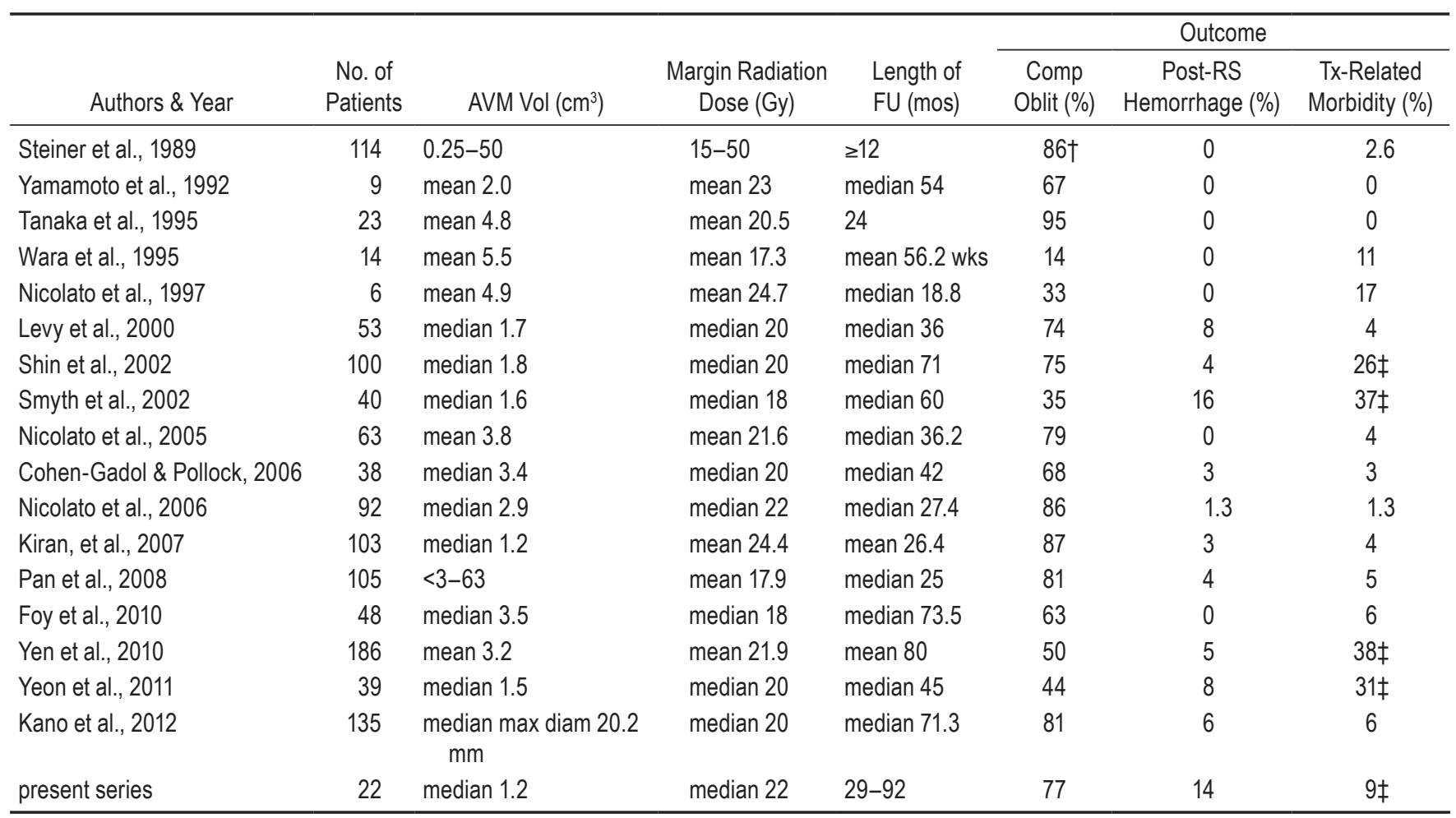

* Comp Oblit = complete obliteration; diam = diameter; FU = follow-up; Post-RS = postradiosurgery; Tx = treatment..

$\dagger$ In the subgroup of patients followed up for $\geq 2$ years after so-called optimal treatment, defined as full coverage of the AVM with a margin dose of $>$ 25 Gy (50 cases).

$\ddagger$ Mainly perilesional hyperintensity found on T2-weighted MR imaging in patients with no symptoms. 
and time intervals between different radiosurgical sessions. For example, the Pittsburgh group and its followers proposed division of a large AVM into 2 approximately equal volumes, preferably corresponding to territories of supplying arteries, and treating each portion with an average interval between irradiation of 3-6 months; they suggested starting with the "deepest," "medial," or "proximal" portion of nidus and selecting the dose according to the PIV. ${ }^{1,5,23}$ In contrast, Back et al. ${ }^{2}$ recommended sequential use of several relatively small targets, using sufficiently large radiation doses at each stage and separating the sessions by 2-month intervals. In some other reported series the details of the staged-volume radiosurgery were not provided at all, and therefore we cannot exclude the possibility that the patients were treated without any predetermined strategy.

Meanwhile, it has not yet been clearly defined as to which portion of nidus should be targeted first (adjacent to feeding arteries, at the center, or in the vicinity of draining veins). Our concept of staged-volume $\mathrm{GKS}^{14-16}$ was originally based on the experience of the Marseille group. The main idea of initially targeting the nidus in the vicinity of the draining vein is related to obtaining the desired effect on the shunts. In this way, the treatment effects of radiosurgery may be realized not only through irradiation-induced proliferation of vascular walls, but also through hemodynamic changes, with a gradual slowing down of intralesional blood flow, hypoperfusion of the AVM, and subsequent thrombosis of the lesion. In our experience with such a technique in both adults and children, the lesion frequently was obliterated following the first stage of treatment, despite the fact that there was incomplete coverage of the nidus with the prescribed isodose, making subsequent radiosurgical sessions unnecessary. ${ }^{16}$ Therefore, we advocate observation for 3-4 years after the initial GKS, postponing a final evaluation of the treatment effects and the decision on further strategy until completion of the latency period. Only in cases of AVMs with intraventricular extension, which have a propensity to bleed, do we propose earlier commencement of the second stage of GKS. If a second radiosurgical session seems necessary, it is conducted according to the same principles as the first. In fact, using our proposed treatment strategy each new target within the nidus can be managed as a virgin treatment, since no dose adjustment is necessary. The PIV is constantly kept lower than $4.0 \mathrm{~cm}^{3}$ so that a sufficiently high dose of radiation can be delivered (usually 22 Gy directed to the 50\% isodose line).

In the present series 13 children were treated according to the described technique of staged-volume GKS. In 4 patients, complete obliteration of the nidus was noted after the first stage of treatment, and in 5 children it was observed after the second one. In the other patients the goal of treatment has still not been attained, but additional radiosurgical sessions will be conducted in the future if required. Certainly, these lesions are still at risk for bleeding, since no data support a reduction in the hemorrhage rate until total obliteration of the nidus. ${ }^{21}$ Therefore, the opponents of staged-volume GKS frequently emphasize the risk of hemorrhage after incomplete treatment of AVMs. In fact, 2 (15\%) of 13 patients in the present se- ries, who were initially scheduled for staged radiosurgery, experienced intracerebral hemorrhage during long-term follow-up after irradiation of the target. The annual hemorrhage rate in that subgroup was $2.8 \%$. This rate seems lower than that of a large cohort of patients, mainly adults, who underwent staged-volume GKS in Pittsburgh $(5.1 \%)^{23}$ and just a little higher than the $0.56 \%-2.7 \%$ rates reported in several series of pediatric AVMs treated in a single stage..$^{24,35,41,52,53}$ Therefore, it remains unclear whether incomplete coverage of the nidus increases the risk of postradiosurgery hemorrhage. It should be noted that pediatric AVMs have a high propensity for spontaneous bleeding ${ }^{18,26,28,33,35}$ and that staged radiosurgery is usually applied for lesions that are not amenable to management by other methods.

On the other hand, in cases in which there is preferential targeting of the nidus in the vicinity of the draining vein, the possibility of its early thrombosis should also be seriously considered. ${ }^{5}$ Such a complication may be extremely troublesome, but fortunately, it was never observed in our practice. Therefore, it may be hypothesized that early occlusion of the draining vein after radiosurgery for an AVM is caused by inadvertent irradiation of that vein itself. It should be definitely avoided and only the nidus should be included in the PIV. Use of multiple small isocenters provides a perfect option for selective treatment planning and a steep dose falloff outside the target.

Besides hemorrhage, possible complications during long-term follow-up after GKS for AVMs include radiation-induced necrosis, perilesional edema, delayed cyst formation, seizures, psychiatric abnormalities, cranial neuropathy, arterial stenosis, and radiation-induced tumors. ${ }^{2,8,11,12,20,21,31,41,49,52,53}$ No such case was met in the present series, which may also reflect the advantages of our treatment strategy. The necessity of minimizing the risk of treatment-related morbidity cannot be overemphasized when referring to children with such benign conditions such as AVMs and sufficiently long life expectancy. Meanwhile, in 2 asymptomatic patients (9\%) the appearance of a region of hyperintensity on T2-weighted MRI in the vicinity to the target was noted. Such a finding after radiosurgery for an AVM is encountered in $0.4 \%{ }^{21}$ to $60 \%{ }^{11}$ of cases, but it usually, albeit not always, resolves with time without any additional treatment. ${ }^{28,47,49,52} \mathrm{Fi}$ nally, the appearance of a new nidus in the vicinity of a completely obliterated AVM was noted in 1 patient and it required additional treatment. This situation is rarely described in the literature and probably is caused by nonvisualization of a portion of lesion at the time of treatment, growth of the treated AVM, or formation of a new $\mathrm{AVM}^{4}{ }^{4,13,27,28,31,40}$ The possibility of such a finding, as well as the rare chance of recanalization of the successfully treated AVM, ${ }^{31}$ advocates for prolonged surveillance of patients using MR imaging, even if complete obliteration of the lesion is obtained after radiosurgery.

\section{Conclusions}

Gamma Knife surgery is a highly effective management option for intracranial AVMs in children. In the present series, unstaged treatment in patients with small 
lesions resulted in an $89 \%$ complete obliteration rate. Staged radiosurgery may be successfully applied for the treatment of a larger AVM. In this way, initial targeting of the nidus adjacent to the draining vein and application of a sufficient radiation dose ( $\geq 22$ Gy directed to the $50 \%$ isodose line) to a relatively small volume $\left(\leq 4 \mathrm{~cm}^{3}\right)$ provides a good balance between a high probability of obliteration and a low risk of treatment-related complications.

\section{Disclosure}

This study represents a portion of the Innovative Project of ELEKTA Research Collaboration with Tokyo Women's Medical University/TWIns. The authors report no conflict of interest concerning the materials or methods used in this study or the findings specified in this paper.

Author contributions to the study and manuscript preparation include the following. Conception and design: Hayashi. Acquisition of data: Hayashi, N Tamura. Analysis and interpretation of data: Hayashi, N Tamura, Chernov. Drafting the article: Chernov. Critically revising the article: all authors. Reviewed submitted version of manuscript: all authors. Approved the final version of the manuscript on behalf of all authors: Hayashi. Statistical analysis: $\mathrm{N}$ Tamura. Administrative/technical/material support: M Tamura, Horiba, Konishi. Study supervision: Hayashi, Muragaki, Iseki, Okada.

\section{References}

1. Amponsah K, Ellis TL, Chan MD, Bourland JD, Glazier SS, McMullen KP, et al: Staged gamma knife radiosurgery for large cerebral arteriovenous malformations. Stereotact Funct Neurosurg 89:365-371, 2011

2. Back AG, Vollmer D, Zeck O, Shkedy C, Shedden PM: Retrospective analysis of unstaged and staged Gamma Knife surgery with and without preceding embolization for the treatment of arteriovenous malformations. J Neurosurg 109 Suppl:57-64, 2008

3. Buis DR, Dirven CMF, Lagerwaard FJ, Mandl ES, Lycklama á Nijeholt GJ, Eshghi DS, et al: Radiosurgery of brain arteriovenous malformations in children. J Neurol 255:551-560, 2008

4. Bulsara KR, Alexander MJ, Villavicencio AT, Graffagnino C: De novo cerebral arteriovenous malformation: case report. Neurosurgery 50:1137-1141, 2002

5. Chung WY, Shiau CY, Wu HM, Liu KD, Guo WY, Wang LW, et al: Staged radiosurgery for extra-large cerebral arteriovenous malformations: method, implementation, and results. J Neurosurg 109 Suppl:65-72, 2008

6. Cohen-Gadol AA, Pollock BE: Radiosurgery for arteriovenous malformations in children. J Neurosurg 104 (6 Suppl): 388-391, 2006

7. Darsaut TE, Guzman R, Marcellus ML, Edwards MS, Tian L, Do HM, et al: Management of pediatric intracranial arteriovenous malformations: experience with multimodality therapy. Neurosurgery 69:540-556, 2011

8. Douglas JG, Goodkin R: Treatment of arteriovenous malformations using Gamma Knife surgery: the experience at the University of Washington from 2000 to 2005. J Neurosurg 109 Suppl:51-56, 2008

9. Foy AB, Wetjen N, Pollock BE: Stereotactic radiosurgery for pediatric arteriovenous malformations. Neurosurg Clin $\mathbf{N}$ Am 21:457-461, 2010

10. Ganz JC: Gamma Knife Neurosurgery. Wien: SpringerVerlag, 2010

11. Ganz JC, Reda WA, Abdelkarim K: Adverse radiation effects after Gamma Knife Surgery in relation to dose and volume. Acta Neurochir (Wien) 151:9-19, 2009
12. Gerszten PC, Adelson PD, Kondziolka D, Flickinger JC, Lunsford LD: Seizure outcome in children treated for arteriovenous malformations using gamma knife radiosurgery. Pediatr Neurosurg 24:139-144, 1996

13. Gonzalez LF, Bristol RE, Porter RW, Spetzler RF: De novo presentation of an arteriovenous malformation. Case report and review of the literature. J Neurosurg 102:726-729, 2005

14. Hayashi M, Izawa M, Ochiai T, Chernov M, Higa T, Ujiie H, et al: [The treatment strategy of staged radiosurgery for high grade arteriovenous malformation considering post-radiosurgical complication.] Stereotactic Radiotherapy 9:87-96, 2005 (Jpn)

15. Hayashi M, Kamata K, Nagata O, Yomo S, Ochiai T, Chernov $\mathrm{M}$, et al: [Unique treatment strategy of Gamma Knife treatment for high grade pediatric arteriovenous malformations: advantages of preferentially targeting at the drainer near nidus in staged radiosurgery.] Stereotactic Radiotherapy 11:51-58, 2007 (Jpn)

16. Hayashi M, Tamura N, Yomo S, Higa T, Chernov M, Okada Y, et al: Gamma Knife radiosurgical strategy for pediatric highgrade arteriovenous malformations: advantages of staged radiosurgery prior to targeting nidus proximal to the drainer, in McDermott MW, Sneed PK, Huang K, et al (eds): Radiosurgery. Basel, Switzerland: Karger, 2010, Vol 7, pp 332-340

17. Hoh BL, Ogilvy CS, Butler WE, Loeffler JS, Putman CM, Chapman PH: Multimodality treatment of nongalenic arteriovenous malformations in pediatric patients. Neurosurgery 47:346-358, 2000

18. Humphreys RP, Hoffman HJ, Drake JM, Rutka JT: Choices in the 1990s for the management of pediatric cerebral arteriovenous malformations. Pediatr Neurosurg 25:277-285, 1996

19. Izawa M, Chernov M, Hayashi M, Iseki H, Hori T, Takakura $\mathrm{K}$ : Combined management of intracranial arteriovenous malformations with embolization and gamma knife radiosurgery: comparative evaluation of the long-term results. Surg Neurol 71:43-53, 2009

20. Izawa M, Chernov M, Hayashi M, Nakaya K, Kamikawa S, Kato K, et al: Management and prognosis of cysts developed on long-term follow-up after Gamma Knife radiosurgery for intracranial arteriovenous malformations. Surg Neurol 68:400-406, 2007

21. Izawa M, Hayashi M, Chernov M, Nakaya K, Ochiai T, Murata $\mathrm{N}$, et al: Long-term complications after gamma knife surgery for arteriovenous malformations. J Neurosurg 102 Suppl: 34-37, 2005

22. Kamata K, Hayashi M, Nagata O, Muragaki Y, Iseki H, Okada $\mathrm{Y}$, et al: Initial experience with the use of remote control monitoring and general anesthesia during radiosurgery for pediatric patients. Pediatr Neurosurg 47:158-166, 2011

23. Kano H, Kondziolka D, Flickinger JC, Park KJ, Parry PV, Yang HC, et al: Stereotactic radiosurgery for arteriovenous malformations, Part 6: multistaged volumetric management of large arteriovenous malformations. Clinical article. J Neurosurg 116:54-65, 2012

24. Kano H, Kondziolka D, Flickinger JC, Yang HC, Flannery TJ, Awan NR, et al: Stereotactic radiosurgery for arteriovenous malformations, Part 2: management of pediatric patients. Clinical article. J Neurosurg Pediatr 9:1-10, 2012

25. Kim BS, Sarma D, Lee SK, terBrugge KG: Brain edema associated with unruptured brain arteriovenous malformations. Neuroradiology 51:327-335, 2009

26. Kiran NA, Kale SS, Vaishya S, Kasliwal MK, Gupta A, Sharma MS, et al: Gamma Knife surgery for intracranial arteriovenous malformations in children: a retrospective study in 103 patients. J Neurosurg 107 (6 Suppl):479-484, 2007

27. Klimo P Jr, Rao G, Brockmeyer D: Pediatric arteriovenous malformations: a 15-year experience with an emphasis on residual and recurrent lesions. Childs Nerv Syst 23:31-37, 2007

28. Kondziolka D, Kano H, Yang HC, Flickinger JC, Lunsford L: 
Radiosurgical management of pediatric arteriovenous malformations. Childs Nerv Syst 26:1359-1366, 2010

29. Kuo YH, Santoreneos S, Roos D, Brophy BP: Treatment of multiple arteriovenous malformations in pediatric patients with hereditary hemorrhagic telangiectasia and spontaneous hemorrhage. Report of two cases. J Neurosurg 107 (6 Suppl): 489-494, 2007

30. Levy EI, Niranjan A, Thompson TP, Scarrow AM, Kondziolka D, Flickinger JC, et al: Radiosurgery for childhood intracranial arteriovenous malformations. Neurosurgery 47:834842,2000

31. Lindqvist M, Karlsson B, Guo WY, Kihlström L, Lippitz B, Yamamoto M: Angiographic long-term follow-up data for arteriovenous malformations previously proven to be obliterated after gamma knife radiosurgery. Neurosurgery 46:803-810, 2000

32. Massager N, Maris C, Nissim O, Devriendt D, Salmon I, Levivier M: Experimental analysis of radiation dose distribution in radiosurgery: I. Dose hot spot inside target volume. Stereotact Funct Neurosurg 87:82-87, 2009

33. Nicolato A, Foroni R, Seghedoni A, Martines V, Lupidi F, Zampieri $\mathrm{P}$, et al: Leksell gamma knife radiosurgery for cerebral arteriovenous malformations in pediatric patients. Childs Nerv Syst 21:301-308, 2005

34. Nicolato A, Gerosa M, Ferraresi P, Piovan E, Pasoli A, Perini $\mathrm{S}$, et al: Stereotactic radiosurgery for the treatment of arteriovenous malformations in childhood. J Neurosurg Sci 41:359371, 1997

35. Nicolato A, Lupidi F, Sandri MF, Foroni R, Zampieri P, Mazza $\mathrm{C}$, et al: Gamma knife radiosurgery for cerebral arteriovenous malformations in children/adolescents and adults. Part I: Differences in epidemiologic, morphologic, and clinical characteristics, permanent complications, and bleeding in the latency period. Int J Radiat Oncol Biol Phys 64:904-913, 2006

36. Nicolato A, Lupidi F, Sandri MF, Foroni R, Zampieri P, Mazza $\mathrm{C}$, et al: Gamma Knife radiosurgery for cerebral arteriovenous malformations in children/adolescents and adults. Part II: Differences in obliteration rates, treatment-obliteration intervals, and prognostic factors. Int J Radiat Oncol Biol Phys 64:914-921, 2006

37. Pan DHC, Kuo YH, Guo WY, Chung WY, Wu HM, Liu KD, et al: Gamma Knife surgery for cerebral arteriovenous malformations in children: a 13-year experience. J Neurosurg Pediatr 1:296-304, 2008

38. Pollock BE, Flickinger JC: A proposed radiosurgery-based grading system for arteriovenous malformations. J Neurosurg 96:79-85, 2002

39. Reyns N, Blond S, Gauvrit JY, Touzet G, Coche B, Pruvo JP, et al: Role of radiosurgery in the management of cerebral arteriovenous malformations in the pediatric age group: data from a 100-patient series. Neurosurgery 60:268-276, 2007

40. Rodríguez-Arias C, Martínez R, Rey G, Bravo G: Recurrence in a different location of a cerebral arteriovenous malformation in a child after radiosurgery. Childs Nerv Syst 16:363365,2000

41. Shin M, Kawamoto S, Kurita H, Tago M, Sasaki T, Morita A, et al: Retrospective analysis of a 10 -year experience of stereotactic radio surgery for arteriovenous malformations in children and adolescents. J Neurosurg 97:779-784, 2002

42. Smyth MD, Sneed PK, Ciricillo SF, Edwards MS, Wara WM,
Larson DA, et al: Stereotactic radiosurgery for pediatric intracranial arteriovenous malformations: the University of California at San Francisco experience. J Neurosurg 97:48-55, 2002

43. Spetzler RF, Martin NA: A proposed grading system for arteriovenous malformations. J Neurosurg 65:476-483, 1986

44. Spetzler RF, Ponce FA: A 3-tier classification of cerebral arteriovenous malformations. Clinical article. J Neurosurg 114: 842-849, 2011

45. Steiner L, Lindquist C, Steiner M: Stereotactic radiosurgery. Part 1: Radiosurgery with focused gamma-beam irradiation in children, in Edwards MSB, Hoffman HJ (eds): Cerebral Vascular Disease in Children and Adolescents. Baltimore: Williams \& Wilkins, 1989, pp 367-388

46. Tanaka T, Kobayashi T, Kida Y, Oyama H, Niwa M: [The comparison between adult and pediatric AVMs treated by gamma knife radiosurgery.] No Shinkei Geka 23:773-777, 1995 (Jpn)

47. Tranchida JV, Mehall CJ, Slovis TL, Lis-Planells M: Imaging of arteriovenous malformation following stereotactic radiosurgery. Pediatr Radiol 27:299-304, 1997

48. Valle RD, Zenteno M, Jaramillo J, Lee A, De Anda S: Definition of the key target volume in radiosurgical management of arteriovenous malformations: a new dynamic concept based on angiographic circulation time. J Neurosurg 109 Suppl:41-50, 2008

49. Wara W, Bauman G, Gutin P, Circillo S, Larson D, McDermott M, et al: Stereotactic radiosurgery in children. Stereotact Funct Neurosurg 64 (1 Suppl 1):118-125, 1995

50. Wegner RE, Oysul K, Pollock BE, Sirin S, Kondziolka D, Niranjan A, et al: A modified radiosurgery-based arteriovenous malformation grading scale and its correlation with outcomes. Int J Radiat Oncol Biol Phys 79:1147-1150, 2011

51. Yamamoto M, Jimbo M, Ide M, Tanaka N, Lindquist C, Steiner L: Long-term follow-up of radiosurgically treated arteriovenous malformations in children: report of nine cases. Surg Neurol 38:95-100, 1992

52. Yen CP, Monteith SJ, Nguyen JH, Rainey J, Schlesinger DJ, Sheehan JP: Gamma Knife surgery for arteriovenous malformations in children. Clinical article. J Neurosurg Pediatr 6: 426-434, 2010

53. Yeon JY, Shin HJ, Kim JS, Hong SC, Lee JI: Clinico-radiological outcomes following gamma knife radiosurgery for pediatric arteriovenous malformations. Childs Nerv Syst 27:1109-1119, 2011

Manuscript submitted May 15, 2012.

Accepted July 18, 2012.

The results of this study were presented during the 16th International Meeting of the Leksell Gamma Knife Society, March 25-29, 2012, in Sydney, Australia.

Please include this information when citing this paper: DOI: 10.3171/2012.7.GKS12998.

Address correspondence to: Motohiro Hayashi, M.D., D.Med.Sci., Department of Neurosurgery, Neurological Institute, Tokyo Women's Medical University, 8-1 Kawada-cho, Shinjukuku, Tokyo 162-8666. Japan. email: GKRmoto@gmail.com. 